\title{
A urgente e imperiosa modificação no cuidado à saúde da pessoa idosa
}

\author{
The urgent and imperative change in the health care of the elderly
}

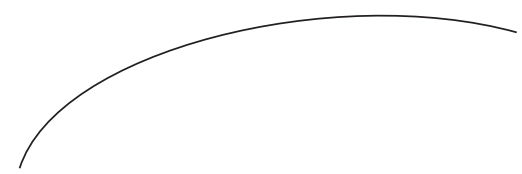

$\mathrm{Na}$ condição de diretor da UnATI/UERJ e editor da RBGG, no primeiro número de cada ano costumo escrever o editorial da revista, que expressa, mais do que uma opinião, a tendência que depreendemos que irá se consolidar na organização dos modelos assistenciais para o idoso. $\mathrm{Na}$ maioria das vezes, recebo comentários elogiosos, mas quase sempre vem um comentário secundário - "o que você escreve é tão óbvio que talvez por isso seja tão difícil efetivar essas ideias”. Tendo a concordar com esta apreciação, e por entender que as mudanças, a cada ano que passa, são cada vez mais necessárias, estou novamente apresentando uma reflexão para o público acadêmico e formador de opinião que acompanha a Revista Brasileira de Geriatria e Gerontologia, pois ainda precisamos de mais uma dose do remédio, que, espero, leve à cura do nosso modelo assistencial.

Sabemos que quanto mais o profissional de saúde conhece o histórico do seu paciente, melhores serão os resultados. Um jeito diferente e inovador de cuidar da saúde e proporcionar qualidade de vida aos usuários, seja no Sistema Único de Saúde ou no setor privado, envolve a utilização de pessoal qualificado e bem preparado. É assim que devem funcionar os modelos contemporâneos e resolutivos de cuidado - que, aliás, são recomendados pelos mais importantes organismos nacionais e internacionais de saúde.

O envelhecimento da população gera novas demandas para os sistemas de saúde. Pessoas mais velhas têm necessidades específicas, advindas das características clínico-funcionais e sócio-familiares peculiares a esse grupo etário. Os problemas de saúde dos idosos - maiores vítimas dos efeitos de sua própria fragilidade - desafiam os modelos tradicionais de cuidado. Os avanços da tecnologia, da ciência e da medicina oferecem àqueles que utilizam as modernas ferramentas para a manutenção da saúde a chance de desfrutar a vida por um tempo maior. Assim, as estratégias de prevenção ao longo de todo o curso da vida se tornam mais importantes para resolver os desafios de hoje e, de forma progressiva, os de amanhã.

As transformações sociais e econômicas das últimas décadas, suas consequentes alterações nos estilos de vida das sociedades contemporâneas - mudança dos hábitos alimentares, aumento do sedentarismo e do estresse - e a crescente expectativa de vida da população colaboraram para a maior incidência das enfermidades crônicas, que hoje constituem um sério problema de saúde pública. Doenças cardiovasculares e respiratórias, câncer e diabetes são as maiores responsáveis pela mortalidade no mundo. No Brasil, nas últimas décadas, as doenças crônicas não transmissíveis tornaram-se as principais causas de óbito e incapacidade prematura. Não é possível atender a esse público de forma satisfatória ignorando que essa parcela da sociedade necessita de uma assistência diferenciada. Por isso é imperativo repensar o modelo atual. 
A prestação de serviços de saúde, atualmente, fragmenta a atenção ao idoso, com multiplicação de consultas de especialistas, inúmeros fármacos, exames e outros procedimentos. Sobrecarrega o sistema, provoca forte impacto financeiro em todos os níveis e não gera benefícios significativos para a qualidade de vida.

Quando observamos o orçamento da Saúde, de maneira geral, verificamos que quase a totalidade dos recursos é aplicada nos hospitais e nas aparelhagens para os exames complementares. A sociedade e os profissionais de saúde seguem, em regra, uma lógica "hospitalocêntrica" - entendem apenas de tratar da doença, não de evitar seu surgimento. $O$ hospital é visto como o local privilegiado da cura, o que é um erro conceitual. A instituição hospitalar não pode ser a porta de entrada do sistema.

Sabemos que o idoso tem muitas doenças e, naturalmente, utiliza muito os serviços de saúde. Então devemos oferecer um cuidado em instâncias mais leves, sempre que possível em caráter preventivo, fora do ambiente hospitalar. Envelhecer, ainda que sem doenças crônicas, envolve alguma perda funcional, que é expressa por diminuição de vigor, força, prontidão, velocidade de reação sistêmica e eficiência metabólica.

Nossa proposta é que o modelo de atenção ao idoso tenha como foco a identificação de riscos potenciais. Ao monitorarmos a saúde em vez da doença, direcionamos o investimento dos recursos do sistema de saúde para uma intervenção precoce, o que resulta em chances mais generosas de reabilitação e em redução do impacto na funcionalidade.

Como consequência de uma população mais envelhecida, a promoção e a educação em saúde, a prevenção e o retardamento de doenças e fragilidades, a manutenção da independência e da autonomia são ações que precisam ser ampliadas. Afinal, não basta o aumento da longevidade; é essencial que os anos adicionais sejam vividos com qualidade, dignidade e bem-estar. 